\title{
Liquid Biopsy beim Mammakarzinom
}

\section{Liquid Biopsy in Breast Cancer}

\section{(c) $(9)$}

\author{
Autoren \\ Maggie Banys-Paluchowski ${ }^{1}$, Natalia Krawczyk ${ }^{2}$, Tanja Fehm² \\ Institute \\ 1 Frauenklinik, Asklepios Klinik Barmbek, Hamburg \\ 2 Universitäts-Frauenklinik, Universitätsklinikum Düsseldorf, \\ Düsseldorf
}

\section{Schlüsselwörter}

Liquid Biopsy, Mammakarzinom, zirkulierende Tumor-DANN, zirkulierende Tumorzelle, zielgerichtete Therapie

\section{Key words}

liquid biopsy, breast cancer, circulating tumour DNA, circulating tumour cell, targeted therapy

\section{Bibliografie}

TumorDiagn u Ther 2021; 42: 361-372

DOI $10.1055 / a-1467-0165$

ISSN $0722-219 X$

(c) 2020. The Author(s).

This is an open access article published by Thieme under the terms of the Creative Commons Attribution-NonDerivative-NonCommercial-License, permitting copying and reproduction so long as the original work is given appropriate credit. Contents may not be used for commecial purposes, or adapted, remixed, transformed or built upon. (https://creativecommons.org/licenses/by-nc-nd/4.0/)

Georg Thieme Verlag KG, Rüdigerstraße 14,

70469 Stuttgart, Germany

Zitierweise für diesen Artikel Geburtsh Frauenheilk 2020; 80: 1093-1104; doi 10.1055/a-1124-7225

Korrespondenzadresse

Priv.-Doz. Dr. Maggie Banys-Paluchowski

Frauenklinik

Asklepios Klinik Hamburg-Barmbek, Rübenkamp 220,

22307 Hamburg, Deutschland

m.banys@outlook.com

\section{ZUSAMMENFASSUNG}

In den letzten Jahren gewinnt die Liquid Biopsy, d. h. die blutbasierte Untersuchung von zirkulierenden Tumorzellen (CTCS) und Nukleinsäuren (DNA/RNA) beim Mammakarzinom zunehmend an Relevanz. Zahlreiche Studien haben bereits die hohe prognostische Bedeutung der CTC-Detektion sowohl im frühen als auch metastasierten Stadium gezeigt. Des Weiteren korrelieren die Veränderungen der CTC-Zahlen und der zirkulierenden Tumor-DNA (ctDNA) im Verlauf der Erkrankung mit dem Ansprechen auf die Therapie. Im Fokus der Forschung stehen derzeit die Liquid-Biopsy-basierten Therapieinterventionen beim metastasierten Mammakarzinom. In diesem Kontext wurde Alpelisib, ein PI3K-Inhibitor, als erste Substanz durch die FDA und die EMA zugelassen.

\section{ABSTRACT}

In recent years, the blood-based analysis of circulating tumour cells (CTCS) and nucleic acids (DNA/RNA), otherwise known as liquid biopsy, has become increasingly important in breast cancer. Numerous trials have already underscored the high prognostic significance of CTC detection in both early and metastatic stages. Moreover, the changes in CTC levels and circulating tumour DNA (ctDNA) during the course of the disease correlate with the response to treatment. Research currently focuses on liquid-biopsy based therapeutic interventions in metastatic breast cancer. In this context, alpelisib, a PI3K inhibitor, was the first agent to be approved by FDA and EMA.

\section{Einleitung}

Dank wissenschaftlicher und klinischer Erkenntnisse erlebten die Diagnostik und Therapie des Mammakarzinoms im letzten Jahrhundert einen erheblichen Paradigmenwechsel. Die sog. „Halsted-Doktrin“, die den Brustkrebs als lokales Geschehen und die Heilung in der möglichst radikalen Operation gesehen hatte, wurde von der „Fischer-Doktrin“ abgelöst, die das Mammakarzinom bereits in frühen Stadien als eine systemische Erkrankung betrachtet [1]. So wissen wir heute, dass die hämatogene Streu- ung schon in sehr frühen Brustkrebsstadien stattfindet und die zirkulierenden Tumorzellen (engl. circulating tumor cells = CTCs) sogar bei Patientinnen mit präinvasiven Läsionen der Mamma nachgewiesen werden können [2]. Gleichzeitig besagt die Hypothese der metastatischen Ineffizienz (engl.metastatic inefficiency), dass die meisten dieser Zellen vom Immunsystem oder durch mechanische Scherkräfte des Blutes eliminiert werden [3, 4]. Lediglich eine kleine CTC-Subpopulation ist in der Lage, langfristig im Blut oder in anderen „homing sites“, wie dem Knochenmark, zu persistieren, und gilt als Surrogatmarker der minimalen resi- 
dualen Tumorerkrankung (engl. minimal residual disease=MRD). Diese Zellen können auch sehr lange Zeit in einem sog. Schlafzustand (engl. tumor cell dormancy) verharren und auch viele Jahre nach der Erstdiagnose der Erkrankung im peripheren Blut detektiert werden [5].

Welche Eigenschaften dazu beitragen, dass bestimmte CTCS imstande sind, „aufzuwachen“ und mehrere Schritte der Metastasierungskaskade zu überleben, um später Fernmetastasen zu bilden, bleibt nach wie vor nicht endgültig geklärt. Eine der aktuell diskutierten Theorien besagt, dass es sich hier um besondere aggressive Zellen handelt, welche die sog. epithelial-mesenchymale Transition (EMT) durchlaufen. Hierbei handelt es sich um einen Prozess, der eine Reihe von Veränderungen beinhaltet, beispielsweise den Verlust der Polarität und der interzellulären Adhäsion, eine Zunahme der Mobilität und der Invasivität sowie schließlich den Verlust des epithelialen und Erwerb des mesenchymalen Phänotyps [6]. Des Weiteren können im Rahmen der EMT Zellen mit Stammzelleigenschaften generiert werden, die über einen sehr hohen Selbsterneuerungspotenzial sowie Resistenzmechanismen verfügen und als eigentliche Vorläufer der Fernmetastasierung angesehen werden [7, 8].

\section{Das Konzept der Liquid Biopsy}

Neben den intakten CTCs können auch zirkulierende Tumor-DNA (ctDNA) und/oder RNA-Fragmente (non-coding RNA, ncRNA) im peripheren Blut der Mammakarzinompatientinnen nachgewiesen werden. Diese werden zum einem durch den Primärtumor und/ oder die metastatische Läsion selber und zum anderen durch die zugrunde gehenden CTCs kontinuierlich in die Blutbahn abgegeben. Als Liquid Biopsy wird die Detektion und die Untersuchung dieser blutbasierten Biomarker bei Karzinompatienten bezeichnet. Auf diese Weise können bei heterogenen Tumoren wie dem Mammakarzinom z. B. Mutationen und Amplifikationen von Onkogenen ggf. adäquater als mit einer Gewebebiopsie, die nur ein begrenztes Tumorareal abbildet, nachgewiesen werden $[9,10]$. Weitere Vorteile gegenüber der Gewebebiopsie sind die Möglichkeit der seriellen Untersuchungen durch einfache Blutentnahmen und die Erfassbarkeit multipler bzw. schwer erreichbarer Metastasenherde. Zudem ist die Akzeptanz der Liquid Biopsy aufgrund ihrer geringen Invasivität bei Patientinnen sehr hoch. Im folgenden Beitrag werden die aktuelle Datenlage zur klinischen Relevanz sowie die potenziellen Einsatzmöglichkeiten der Liquid Biopsy beim primären und metastasierten Mammakarzinom vorgestellt.

\section{Nachweismethoden}

\section{Zirkulierende Tumorzellen}

Der Nachweis von CTCs erfolgt grundsätzlich in 2 voneinander unabhängigen Schritten: Isolation der Zellen aus dem Vollblut und ihre eigentliche Detektion. Zur Isolation der Zellen von den anderen Blutbestandteilen werden verschiedene, hauptsächlich physikalische (größe- und/oder dichtebasierte) und biologische (Expression bestimmter Antigene) Zelleigenschaften genutzt. Als Beispiele können hier die sog. Dichtegradiententechnik mit Ficoll
- Tab. 1 Beispiele typischer zytomorphologischer Kriterien zur Identifikation der isolierten Tumorzellen (modifiziert nach [13])

\section{Zellmorphologie/Phänotyp}

- Zellkern-Vergrößerung

- große Nukleoli

- Zell-Cluster

- Färbung des Zytoplasmas stark und/oder unregelmäßig

- unregelmäßige, granulierte Struktur des Zellkerns

- Größe der Zelle > Größe der hämatopoetischen Zellen

- Zellkern partiell durch immunzytologische Färbung bedeckt

- netzartige Struktur der Zytokeratinfilamente

oder antigenbasierte Methoden mit epithelialen (z. B. EpCAM, Zytokeratine) und/oder tumorspezifischen Markern, wie CEA oder HER2, genannt werden. Bei der Antikörper-basierten Isolierung werden die spezifischen Antikörper meist an magnetische Partikel gekoppelt, um dann mithilfe eines Magnetfeldes die angereicherten Zellen zu separieren und weiter zu analysieren.

Die anschließende CTC-Detektion kann dann wiederum Nukleinsäure-basiert (RT-PCR, qRT-PCR, Multiplex-RT-PCR) oder anhand der Antigen-Charakteristik (Immunzytochemie, Immunfluoreszenz, Immunfluoreszenz-Durchflusszytometrie) der CTCs erfolgen. Während die Sensitivität und Spezifität der Nukleinsäurebasierten Nachweisverfahren sehr hoch ist, besteht deren Nachteil darin, dass die CTCs im Rahmen der Analyse lysiert werden, sodass eine Beurteilung der Zellmorphologie oder weitere Zellanalysen nicht möglich sind.

Die am häufigsten in klinischen Studien eingesetzte Technik zum CTC-Nachweis stellt das für metastasiertes Mamma-, Darmund Prostatakarzinom von der US-amerikanischen Kontrollbehörde FDA zugelassene CellSearch-System (Menarini Silicon Biosystems, Inc.) dar. Mithilfe dieses standardisierten Assays werden die EpCAM-positiven CTCs immunomagnetisch aus den $7,5 \mathrm{ml}$ venösen Vollblutes isoliert und anschließend mit Antikörpern gegen Zytokeratine (CK) 8, 18, 19, dem spezifischen LeukozytenMarker CD45 und dem Zellkern-Marker DAPI immunfluoreszent gefärbt. Danach wird die Probe durch ein semiautomatisches Fluoreszenzmikroskop gescannt und die potenziellen CTCs automatisch abgebildet. Schließlich erfolgt die Auswertung durch einen erfahrenen Untersucher: CK 8/18/19 und DAPI-positive sowie CD45-negative Zellen, die eine bestimmte Morphologie aufweisen, werden als CTCs identifiziert ( $\vee$ Tab. 1, $\triangleright$ Abb. 1). Die mittels CellSearch detektierten CTCs können per Mikromanipulation gewonnen werden und stehen weiteren Analysen (z. B. Einzelzell-Genexpressionsanalysen) zu Verfügung. Der Nachteil dieser Methode besteht zum einem in der subjektiven Beurteilung des Untersuchers, zum anderen aber auch darin, dass es sich um ein EpCAM-basiertes Verfahren handelt und die Zellen nach EMT (ohne epitheliale Eigenschaften) nicht detektiert werden können $[11,12]$.

Eine weitere Herausforderung der CTC-Diagnostik stellen die niedrige Detektionsraten, in erster Linie im nicht metastasierten Patientenkollektiv, dar. Vor allem in Anbetracht der bekannten Tumorheterogenität ist die Analyse möglichst vieler CTCs einer 

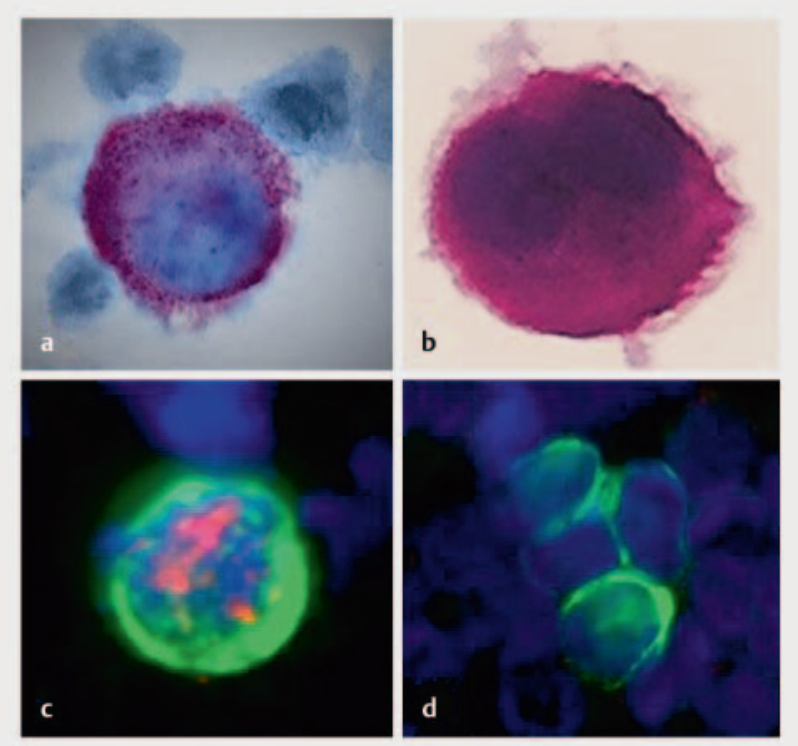

- Abb. 1 Nachweis von isolierten Tumorzellen über verschiedene Detektionsverfahren: a Immunzytochemisch gefärbte apoptotische Tumorzelle (M30-Antikörper [AK]); b Immunzytochemisch gefärbte vitale Tumorzelle (Anti-Zytokeratin [CK]-AK); c Immunfluoreszenz, Doppelfärbung (Anti-CK-AK: grün, Anti-Östrogenrezeptor-AK: rot); d Immunfluoreszent gefärbtes Tumorzell-Cluster (Anti-CK-AK).

Patientin anstrebenswert. In diesem Kontext wurden in den letzten Jahren viele Anreicherungs-/Isolationsmethoden zur Erhöhung der Detektionsrate untersucht. Einen anderen möglichen Ansatz stellt die Analyse größerer Blutvolumina dar, z. B. im Rahmen einer diagnostischen Leukapherese (DLA). Im Rahmen dieses Verfahrens können im Schnitt $2770 \mathrm{ml}$ Blut extrakorporal gefiltert werden. Die CTCs werden hier Dichtegradient-basiert isoliert und ein Aliquot des DLA-Produktes anschließend mittels CellSearch-Systems untersucht. So können die CTC-Detektionsraten und die Anzahl der nachgewiesenen CTCs signifikant erhöht werden [14]. Allerdings ist die Untersuchung großer Blutvolumina mit einem erhöhten Zeitaufwand für die Patientin verbunden: So dauert die Prozedur ca. 1 Stunde. Ferner werden Laborveränderungen nach der DLA beobachtet, wie z. B. geringfügiger Abfall der Leukozytenzahlen und des Hämoglobins, die klinisch nicht relevant sind. Inwiefern sich die Gewinnung von mehreren Tausend CTCs auf die klinische Bedeutung auswirkt und ob die DLA die CTC-basierte Diagnostik verbessern wird, bleibt abzuwarten.

\section{Zirkulierende Tumor-DNA}

Der Begriff zirkulierende Tumor-DNA (ctDNA) definiert im Blut und anderen Körperflüssigkeiten nachweisbare, freie DNA-Fragmente, die aus dem Tumor stammen (Primärtumor, Metastase, isolierte Tumorzellen). Zu unterscheiden davon ist der übergeordnete Begriff zellfreie DNA (cfDNA) bzw. freie zirkulierende DNA (fcDNA), worunter man alle zellfreien DNA-Fragmente, nicht tumorspezifisch, versteht. Auch normale Zellen, die zugrunde gehen, können cfDNA ins Blut abgeben. Während sich die älteren Studien vor allem mit der Detektion der Gesamtmenge der frei zir- kulierenden DNA im Blut befassten, richtet sich der Fokus der neueren Studien auf die spezifischen Nachweismethoden der ctDNA.

Die Detektion erfolgt in der Regel aus dem Blutplasma. Für den Nachweis ist der Anteil der ctDNA im Vergleich zu zellfreier DNA aus normalen Zellen entscheidend. Da dieser zum Teil sehr gering sein kann, bedarf der ctDNA-Nachweis hochsensitiver Detektionsmethoden. Dazu gehören u. a. Digital-droplet PCR (ddPCR), Beads Amplification Magnetics-PCR (BEAMing-PCR) und Digital Nextgeneration Sequencing (dNGS) [15-17]. Hierbei stellen die ddPCR und BEAMing-PCR die sog. zielgerichteten Detektionsverfahren (targeted approach) dar, bei welchen nur wenige Genloci simultan untersucht werden können. Dies bedeutet, dass hier gezielt nach bestimmten, bereits bekannten Tumormutationen z. B. in den Genen PIK3CA, ESR1, AKT1, ERBB2 oder PTEN gesucht wird. Der Begriff dNGS fasst hingegen mehrere genanalytische, nicht zielgerichtete Verfahren zusammen (untargeted approach), im Rahmen derer große DNA-Moleküle sequenziert werden und somit eine Vielzahl unbekannter genetischer Alterationen bzw. Mutationen detektiert werden können. Dazu gehören beispielsweise Array$\mathrm{CGH}$ (Array-Comparative-Genomic-Hybridization), Gesamtgenomsequenzierung (engl. whole-genome sequencing) oder Exomsequenzierung. Mit diesen Methoden werden in der Regel Genmutationen identifiziert, die zur Abklärung von Resistenzentwicklung beitragen können $[15,16]$.

\section{Klinische Einsatzgebiete der Liquid Biopsy beim frühen Mammakarzinom}

\section{Verbesserung der Prognoseeinschätzung}

Das Erreichen der Blutgefäße durch einzelne Tumorzellen und die nachfolgende Dissemination stellen wichtige Schritte der Metastasierungskaskade dar. Dabei können Studien zufolge bereits präinvasive Läsionen der Mamma, wie das duktale Carcinoma in situ (DCIS), von einer Tumorzellstreuung begleitet werden $[2,18]$, sodass die hämatogene Tumorzelldissemination als frühes Ereignis im Verlauf einer Tumorerkrankung angesehen wird. Zirkulierende Tumorzellen können bei 20-30\% der Patientinnen mit nicht metastasiertem Mammakarzinom mithilfe des Cellsearch-Systems detektiert werden [19] ( $\bullet$ Tab. 2). Janni et al. konnten in einer gepoolten Analyse die Daten von 3173 Mammakarzinompatientinnen im Stadium I-III auswerten und zeigen, dass der Nachweis von mindestens einer CTC in 7,5 ml Blut ein deutlich schlechteres klinisches Outcome voraussagt [19]. So war das Risiko, am Mammakarzinom zu versterben, bei CTC-positiven Patientinnen doppelt so hoch wie bei Frauen, die keine CTCs zum Zeitpunkt der Diagnose aufwiesen (Hazard Ratio [HR]: 2,04; $95 \%-\mathrm{KI}$ : 1,52-2,75). Die CTC-Positivität korrelierte ebenfalls mit einem statistisch signifikant kürzeren Gesamtüberleben (HR 1,97; $95 \%$ $\mathrm{KI}$ : 1,51-2,59), krankheitsfreien Überleben (HR 1,82; $95 \%-\mathrm{KI}$ : 1,47-2,26) und fernmetastasenfreien Überleben (HR 1,89; $95 \%$ KI: 1,49-2,40).

Während die prognostische Relevanz der CTCs in großen Metaanalysen ( $\vee$ Tab. 2 ) bestätigt wurde, ist die bisherige Datenlage bez. der zirkulierenden DNA deutlich weniger umfassend ( Tab. 3). In einer 2018 veröffentlichten Metaanalyse von Tan et 
- Tab.2 Prognostische Bedeutung der zirkulierenden Tumorzellen bei Mammakarzinom: die wichtigsten Studien.

\begin{tabular}{|c|c|c|c|c|c|}
\hline Studie & $\begin{array}{l}\text { Anzahl der } \\
\text { Patientinnen }\end{array}$ & Stadium & $\begin{array}{l}\text { Positivitätsrate } \\
\text { n (\%) }\end{array}$ & Assay & $\begin{array}{l}\text { Korrelation mit } \\
\text { der Prognose }\end{array}$ \\
\hline Janni et al. [19] & 3173 & Stadium I-III & $641(20 \%)^{1}$ & CellSearch & DFS, DDFS, BCSS, OS \\
\hline Cristofanilli et al. [20] & 2436 & Stadium IV & $1099(45,1 \%)^{2}$ & CellSearch & OS \\
\hline Bidard et al. [21] & 1574 & $\begin{array}{l}\text { Stadium I-III vor } \\
\text { neoadjuvanter } \\
\text { Chemotherapie }\end{array}$ & $398(25,2 \%)^{1}$ & CellSearch & $\begin{array}{l}\text { OS, DDFS, LRRFS; pCRRate } \\
\text { höher bei CTC-Positivität } \\
\text { ( } 24,2 \text { vs. } 17,4 \%)\end{array}$ \\
\hline \multicolumn{6}{|c|}{$\begin{array}{l}\text { BCSS - brustkrebsspezifisches Überleben; DDFS - fernmetastasenfreies Überle } \\
\text { Überleben; OS - Gesamtüberleben; PCR - pathologische Komplettremission. } \\
1 \text { definiert als } \geq 1 \text { CTC pro } 7,5 \mathrm{ml} \text {. } \\
2 \text { definiert als } \geq 5 \text { CTCs pro } 7,5 \mathrm{ml} \text {. }\end{array}$} \\
\hline
\end{tabular}

- Tab. 3 Prognostische Relevanz der zirkulierenden DNA bei Patientinnen mit Mammakarzinom (modifiziert nach: [22], berücksichtigt wurden nur Studien mit mindestens 100 Patientinnen).

\begin{tabular}{|c|c|c|c|c|}
\hline Studie & $\begin{array}{l}\text { Anzahl der } \\
\text { Patientinnen }\end{array}$ & Setting & Methode & prognostische Relevanz: OS \\
\hline Fujita et al. [23] & 336 & Stadium I-II & $\begin{array}{l}\text { OSMSP1 }^{1} \\
\text { Met-DNA }( \pm) / \text { Gesamt } \\
\text { cfDNA (high/low) }\end{array}$ & $\begin{array}{l}\text { OS: } \\
\text { ja (HR für Met-DNA 3,17, für Gesamt } \\
\text { cfDNA 4,03) } \\
\text { DFS/RFS: } \\
\text { Met-DNA: nein (HR 2,23) Gesamt } \\
\text { cfDNA: ja }(2,70)\end{array}$ \\
\hline $\begin{array}{l}\text { Fernandaz-Garcia } \\
\text { et al. [24] }\end{array}$ & 194 & Stadium IV & $\begin{array}{l}\text { TaqMan, RT-PCR } \\
\text { Gesamt cfDNA } \\
\text { (high/low) }\end{array}$ & $\begin{array}{l}\text { OS: } \\
\text { ja (HR 2,296) }\end{array}$ \\
\hline BRE12-158 [25] & 151 & $\begin{array}{l}\text { Stadium I-III triple- } \\
\text { negativ, non-pCR }\end{array}$ & $\begin{array}{l}\text { Foundation One Liquid }{ }^{2} \\
\text { ctDNA }( \pm)\end{array}$ & $\begin{array}{l}\text { OS: } \\
\text { ja (HR 2,7) } \\
\text { DDFS: ja }(\text { HR 3,1) }\end{array}$ \\
\hline Garcia et al. [26] & 142 & Stadium I-III & $\begin{array}{l}\text { PCR-SSCP }{ }^{2} \\
\text { CtDNA }( \pm)\end{array}$ & $\begin{array}{l}\text { OS: } \\
\text { nein (HR 1,60) } \\
\text { DFS/RFS: } \\
\text { ja (HR } 2,70)\end{array}$ \\
\hline Fujita et al. [27] & 120 & $\begin{array}{l}\text { Stadium II-III } \\
\text { nach Therapie }\end{array}$ & $\begin{array}{l}\text { OSMSP1 } \\
\text { Met-DNA }( \pm) / \text { Gesamt } \\
\text { cfDNA (high/low) }\end{array}$ & $\begin{array}{l}\text { OS: } \\
\text { ja (HR für Met-DNA 4,91, für Gesamt } \\
\text { cfDNA 4,11) } \\
\text { DFS/RFS: } \\
\text { ja (HR für Met-DNA 4,23, für Gesamt } \\
\text { cfDNA } 1,93 \text { ) }\end{array}$ \\
\hline Shaw et al. [28] & 112 & Stadium IV & $\begin{array}{l}\text { ddPCR }^{2} \\
\text { gesamt cfDNA }\end{array}$ & $\begin{array}{l}\text { OS: } \\
\text { ja (HR 2,20) }\end{array}$ \\
\hline Oshiro et al. [29] & 110 & Stadium I-III & $\begin{array}{l}\mathrm{dPCR}^{1} \\
\text { mut. PIK3CA }( \pm)\end{array}$ & $\begin{array}{l}\text { OS: } \\
\text { nein (HR 3,92) } \\
\text { DFS/RFS: } \\
\text { ja (HR 4,78) }\end{array}$ \\
\hline \multicolumn{5}{|c|}{$\begin{array}{l}\text { dPCR - Digital PCR; HR - Hazard Ratio; OSMSP - One-step methylation-specific PCR; PCR-SSCP - PCR-Single-strand Conformation Polymorphism; } \\
\text { RFS - rezidivfreies Überleben (relapse-free survival). } \\
1 \text { Serum. } \\
2 \text { Plasma. }\end{array}$} \\
\hline
\end{tabular}


- Tab. 4 Klinische Bedeutung der persistierenden CTCs beim frühen Mammakarzinom.

\begin{tabular}{|c|c|c|c|c|}
\hline Studie & $\begin{array}{l}\text { Anzahl der } \\
\text { Patientinnen }\end{array}$ & Setting & $\begin{array}{l}\text { Positivitätsrate } \\
\text { (\%) }\end{array}$ & $\begin{array}{l}\text { Korrelation mit } \\
\text { Überleben }\end{array}$ \\
\hline Rack et al. [31] & 1493 & $\begin{array}{l}\text { Stadium I-III N+ oder High-risk N0 Blutent- } \\
\text { nahme nach der adjuvanten Chemotherapie }\end{array}$ & $22 \% 1$ & ja: DFS, OS \\
\hline Bidard et al. [21] & 1200 & Stadium I-III Blutentnahme nach der NACT & $15 \%$ & ja: OS, DDFS \\
\hline Riethdorf et al. [32] & 207 & High-risk Blutentnahme nach der NACT & $11 \%$ & nicht untersucht \\
\hline Kasimir-Bauer et al. [33] & 133 & $\begin{array}{l}\text { Stadium II-III Blutentnahme vor und nach der } \\
\text { NACT }\end{array}$ & $8 \%^{2}$ & nein \\
\hline
\end{tabular}

al. wurden insgesamt 1127 Patientinnen aus 10 Studien berücksichtigt, der Großteil im nicht metastasierten Setting [22]. Anders als in den gepoolten Analysen zur Relevanz von CTCs waren hier die Kollektive deutlich kleiner (max. 336 Patientinnen). Zudem wurden unterschiedliche Assays verwendet, sodass der direkte Vergleich der Studien aufgrund ihrer Heterogenität deutlich erschwert ist. So wurde in einem Teil der analysierten Studien die Gesamtmenge der cfDNA bestimmt, während die anderen den Nachweis von vordefinierten genomischen Alterationen untersuchten. Trotz dieser Mängel lässt die Metaanalyse auf eine mögliche prognostische Bedeutung der cfDNA und der Mutationsdetektion beim nicht metastasierten Mammakarzinom schließen.

\section{Therapiemonitoring mittels Liquid Biopsy}

Die nichtinvasive Blutdiagnostik erlaubt serielle Untersuchungen, welche beliebig oft unter einer Behandlung oder nach Abschluss der Therapie erfolgen können. Somit wird ein einzigartiger Einblick in das aktuelle Tumorgeschehen ermöglicht. Da die Systemtherapie einen Selektionsdruck auf die MRD ausübt, kann mittels Blutentnahmen die persistierende Tumorzellpopulation ermittelt werden [30]. Auf diese Weise kann potenziell das Therapieansprechen überwacht werden und es können jene Patientinnen identifiziert werden, die ein erhöhtes Rezidivrisiko aufweisen und möglicherweise von zusätzlichen Behandlungsansätzen profitieren würden.

Mittlerweile wissen wir, dass CTCs in der Lage sind, über die (neo)adjuvante Therapie hinaus zu persistieren (sog. persistierende CTCs, - Tab.4). Die größte bisher durchgeführte Analyse zur CTC-Persistenz im nicht metastasierten Setting erfolgte im Rahmen der in Deutschland initiierten SUCCESS-Studie [31]. Bei 2026 Patientinnen wurden die CTCs mittels CellSearch vor Beginn der adjuvanten Chemotherapie untersucht. Bei 21,5\% der Frauen konnte mindestens eine CTC detektiert werden. Nach Abschluss der Chemotherapie erfolgte eine Blutentnahme bei 1493 Patientinnen. Die Positivitätsrate betrug 22,1\%. Der Nachweis von CTCs vor der Chemotherapie korrelierte mit dem klinischen Outcome (DFS, DDFS, BCSS und OS), aber nur bedingt mit der CTC-Persistenz. So wiesen 76 Patientinnen einen positiven CTC-Status sowohl vor als auch nach der Chemotherapie auf. Bei 936 Frauen waren beide Blutentnahmen CTC-negativ. Bei 491 Patientinnen kam es zu einem Switch des CTC-Status $(+\rightarrow-$ in 238 Fällen und $-\rightarrow+$ in 253 Fällen). Der Nachweis von persistierenden CTCs sagte ein ungünstiges klinisches Outcome voraus (DFS: Hazard Ratio 1,124, $p=0,02$, OS: Hazard Ratio 1,162, $p=0,06)$. Dies lässt die Entwicklung effektiver Resistenzmechanismen durch die Tumorzellen vermuten, welche ihnen erlauben, sich der Wirkung der zytotoxischen Therapie zu entziehen [21, 31]. Zudem wurde in neoadjuvanten Studien gezeigt, dass das CTC-Ansprechen mit dem Ansprechen des Primärtumors auf die Behandlung nicht korreliert.

Zahlreiche kleinere Studien sind der Frage nachgegangen, wie die Bestimmung der zirkulierenden DNA das Therapiemonitoring beim frühen Mammakarzinom ergänzen kann ( $\triangleright$ Tab. 5). Li et al. untersuchten Plasmaproben vor, während und nach der neoadjuvanten Chemotherapie bei 52 Patientinnen und konnten zeigen, dass die Bestimmung der ctDNA nach 2 Zyklen der Therapie mit der pCR-Wahrscheinlichkeit besser korreliert als die radiologische Diagnostik [34]. Ähnliche Ergebnisse wurden von Magbanua et al. berichtet, die ctDNA mittels Ultra-deep Sequencing bei $84 \mathrm{im}$ Rahmen der I-SPY 2-Studie behandelten Patientinnen untersuchten [35]. Bereits 3 Wochen nach Beginn der Therapie zeigte sich ein starker Abfall der ctDNA-Positivitätsrate von 73 auf $35 \%$. Alle Patientinnen, die eine pCR erreichten, waren nach der Chemotherapie ctDNA-negativ. In der Non-pCR-Subgruppe sagte der Nachweis von persistierender ctDNA nach NACT ein deutlich erhöhtes Metastasierungsrisiko voraus (Hazard Ratio 10,4).

\section{Potenzial der Liquid Biopsy in der Nachsorge}

Nach Abschluss der primären Therapie, die meist aus einer Operation und je nach Subtyp Radiatio und Chemotherapie ggf. in Kombination mit zielgerichteter Therapie besteht, kann der behandelnde Arzt heutzutage nur auf die Merkmale der Erkrankung zum Zeitpunkt der Erstdiagnose zurückgreifen, um das verbleibende Rezidivrisiko abschätzen zu können. Weitere Tools, die eine individualisierte Risikoschätzung erlauben würden, stehen nicht zur Verfügung. Demgegenüber steht der ausgeprägte Wunsch der 
- Tab. 5 Klinische Bedeutung der zirkulierenden DNA unter und nach der neoadjuvanten Therapie beim frühen Mammakarzinom: Übersicht der wichtigsten Studien.

\begin{tabular}{|c|c|c|c|c|}
\hline Studie & $\begin{array}{l}\text { Anzahl der } \\
\text { Patientinnen }\end{array}$ & Methode & Positivitätsrate (\%) & Ergebnisse \\
\hline Takahashi et al. [36] & 87 & OS-MSP & $23 \%$ vor NACT & ctDNA-Persistenz mit RCB assoziiert \\
\hline Magbanua et al. [35] & 84 & Ultra-deep Sequencing & $\begin{array}{l}73 \% \text { vor NACT } 9 \% \\
\text { nach NACT }\end{array}$ & $\begin{array}{l}\text { ctDNA-Persistenz3 Wochen nach Beginn der } \\
\text { NACT assoziiert mit pCR (pCR-Rate } 17 \text { vs. } 48 \% \text {, } \\
p=0,012 \text { ); ctDNA-Nachweis nach NACT assozi- } \\
\text { iert mit DDFS }\end{array}$ \\
\hline NeoALTTOStudie [37] & 69 & $\begin{array}{l}\text { Mutationsanalyse } \\
\text { PIK3CA und TP53 } \\
\text { (ddPCR) }\end{array}$ & $\begin{array}{l}41 \% \text { vor NACT } 20 \% \\
2 \text { Wochen nach Beginn } \\
5 \% \text { nach NACT }\end{array}$ & $\begin{array}{l}\text { persistierende ctDNA } 2 \text { Wochen nach Beginn der } \\
\text { NACT mit geringerer PCR-Wahrscheinlichkeit, } \\
\text { aber nicht mit EFS assoziiert }\end{array}$ \\
\hline Garcia-Murillas et al. [38] & 55 & $\begin{array}{l}\text { dPCR, High-depth DNA } \\
\text { Sequencing }\end{array}$ & $\begin{array}{l}69 \% \text { vor NACT } 19 \% \\
2-4 \text { Wochen postop. }\end{array}$ & $\begin{array}{l}\text { ctDNA-Persistenz 2-4 Wochen postop. mit DFS } \\
\text { assoziiert (Hazard Ratio 25,1) }\end{array}$ \\
\hline Li et al. [34] & 52 & $\begin{array}{l}\text { NGS-Panel von } \\
1021 \text { Genen }\end{array}$ & $\begin{array}{l}48 \% \text { vor NACT (die } \\
\text { meisten Mutationen in } \\
\text { den GenenTP53, PIK3CA, } \\
\text { GAB2 und IRS2); ctDNA- } \\
\text { Persistenz in } 70 \% \text { der } \\
\text { initial ctDNA-positiven } \\
\text { Pat. }\end{array}$ & $\begin{array}{l}\text { ctDNA nach } 2 \text { Zyklen sagte das pathologische } \\
\text { Ansprechen voraus (AUC } 0.81 \text { ); höhere Rezidiv- } \\
\text { rate imFalle der ctDNA-Persistenz ( } 50 \text { vs. } 33 \% \text { ) }\end{array}$ \\
\hline Sharma et al. [39] & 30 & $\begin{array}{l}\text { Methylationsanalyse } \\
\text { (Gene BRCA1, MGMT, } \\
\text { GSTP1, Stratifin, MDR1) }\end{array}$ & $\begin{array}{l}\text { Methylierung vor NACT: } \\
76 \% \text { mindestens } 1 \text { Gen; } \\
53 \% \text { (BRCA1), } 37 \% \\
\text { (MGMT), } 43 \% \text { (GSTP1), } \\
83 \% \text { (Stratifin), } 60 \% \\
\text { (MDR1) (76\%) }\end{array}$ & $\begin{array}{l}\text { Tumoransprechen mit einer häufigeren Methy- } \\
\text { lierung vor NACT und Abfall der Methylierung } \\
\text { nach NACT assoziiert }\end{array}$ \\
\hline Moss et al. [40] & 30 & Methylationsanalyse & $80 \%$ vor $\mathrm{NACT}$ & $\begin{array}{l}\text { starker Abfall der cfDNA unter NACT; cfDNA im } \\
\text { letzten Monat der NACT mit der } p C R \text { assoziiert } \\
(p=0,006)\end{array}$ \\
\hline
\end{tabular}

AUC - Area under the Curve; DFS - krankheitsfreies Überleben; ddPCR - digitale Droplet-PCR; dPCR - digitale PCR; DDFS - fernmetastasenfreies Überleben; EFS - ereignisfreies Überleben; NACT - neoadjuvante Chemotherapie; NGS - Next Generation Sequencing; OS-MSP - One-step methylation-specific PCR; RCB - Residual Cancer Burden.

- Tab. 6 Klinische Relevanz der CTC-Persistenz in der Nachsorge.

\begin{tabular}{|c|c|c|c|c|c|}
\hline Studie & Patientenzahl & $\begin{array}{l}\text { Zeitpunkt der } \\
\text { CTC-Bestimmung }\end{array}$ & $\begin{array}{l}\text { Positivitätsrate } \\
\text { (\%) }\end{array}$ & $\begin{array}{l}\text { mediane } \\
\text { Follow-up-Zeit }\end{array}$ & Korrelation mit Prognose \\
\hline $\begin{array}{l}\text { ECOG-ACRIN } \\
\text { E5103 }[47,48]\end{array}$ & $\begin{array}{l}547 \text { HER2-negativ } \\
\text { Stadium II-III }\end{array}$ & $\begin{array}{l}\text { 4,5-7,5 Jahre nach } \\
\text { der Diagnose }\end{array}$ & $4,8 \%$ & 2,6 Jahre & $\begin{array}{l}\text { Rezidivrisiko } 12,7 \times \text { höher bei } \\
\text { Patientinnen mit persistierenden CTCs; } \\
\text { Rezidivrisiko pro Patientin/Jahr im } \\
\text { HR-positiven Kollektiv: } 21,4 \text { vs. } 2,0 \%\end{array}$ \\
\hline SUCCESS-A [49] & $\begin{array}{l}206 \text { Stadium I-III } \\
\text { (high risk) }\end{array}$ & $\begin{array}{l}\text { median } 62 \text { Monate } \\
\text { nach der Diagnose }\end{array}$ & $7,8 \%$ & $1 \mathrm{Jahr}$ & $\begin{array}{l}\text { im HR-positiven Kollektiv: Rezidivrisiko } \\
\text { höher bei CTC-Positivität (Hazard Ratio } \\
5,95 \text { ) }\end{array}$ \\
\hline
\end{tabular}

Patientin, im Rahmen der Nachsorge die Heilungschancen zu erfahren. In diesem Kontext fordern manche Frauen die Bestimmung der klassischen Tumormarker (z. B. CEA, CA 15-3), eine Untersuchung, von der die aktuellen Leitlinien ausdrücklich abraten [41, 42]. Wie die Liquid Biopsy zur besseren Prognoseschätzung in der Nachsorge der asymptomatischen Patientin beitragen kann, wurde in einigen Studien untersucht.

2018 wurden die Daten aus 2 groß angelegten adjuvanten Therapiestudien veröffentlicht, die im Rahmen von translationalen Subprojekten die Relevanz der CTC-Bestimmung 5 Jahre nach der Diagnose untersucht haben $(\triangleright$ Tab. 6). In beiden Studien 
kam das CellSearch-System zum Einsatz. Interessanterweise war die Prognose bei Frauen mit Persistenz der CTCs deutlich schlechter als im CTC-negativen Kollektiv, besonders in der Gruppe der HRpositiven Tumore. So konnte in der US-amerikanischen Studie gezeigt werden, dass das Rezidivrisiko pro Jahr bei Detektion von mind. einer CTC bei $21,4 \%$ lag, verglichen mit nur $2 \%$ bei CTCnegativem Status.

Kleineren Studien zufolge kann auch die zirkulierende DNA zur Risikostratifizierung der asymptomatischen Patientin während der Nachsorge beitragen [43-46]. So konnten Garcia-Murillas et al. an einem Kollektiv von 101 Frauen zeigen, dass serielle Messungen der ctDNA das Rezidivrisiko voraussagen können [44]. Blutentnahmen erfolgten im 1. Jahr alle 3 Monate und wurden alle 6 Monate für 5 Jahre fortgeführt. Die ctDNA-Detektion basierte auf den im Tumorgewebe nachgewiesenen somatischen Mutationen, die mittels $\mathrm{APCR}$ im Blut untersucht wurden. Patientinnen, bei denen ctDNA im Verlauf detektiert wurde, wiesen ein deutlich kürzeres rezidivfreies Überleben auf (Hazard Ratio 16,7, $p<0,001$ ), wobei die ersten Blutproben bei den meisten Frauen nach Abschluss der Chemotherapie zunächst ctDNA-negativ waren. Im Median trat das klinische Rezidiv bzw. die Fernmetastasierung 10,7 Monate nach der 1. ctDNA-positiven Blutprobe auf. Interessanterweise korrelierte der ctDNA-Verlauf nicht mit dem Auftreten von Hirnmetastasen, sodass diese Lokalisation möglicherweise in der Liquid-Biopsy-basierten Detektion „stumm“ bleiben kann.

Auch in der EBLIS-Studie konnte das Potenzial des ctDNAbasierten Monitoring in der Nachsorge bestätigt werden [45]. Hierbei erfolgten Blutentnahmen alle 6 Monate in den ersten 4 Jahren nach Abschluss der Chemotherapie. Die ctDNA-Detektion basierte auf dem Nachweis von individuellen tumorspezifischen Mutationssignaturen, die anhand der Untersuchung der Primärtumoren erstellt wurden. Die Auswertung der klinischen Verläufe bei den ersten 49 Patientinnen zeigte, dass ctDNA im Median 8,9 Monate vor dem lokalen oder fernen Rezidiv nachgewiesen werden konnte.

Noch ist unklar, wie diese Erkenntnisse in der klinischen Routine implementiert werden können bzw. welche diagnostische oder therapeutische Konsequenz aus einem positiven ctDNA-Blutbefund abgeleitet werden sollte. In der britischen c-TRAK TNStudie (NCT03 145 961) erfolgt das Monitoring mittels ctDNA-Testung alle 3 Monate nach Abschluss der Therapie bei triple-negativer Erkrankung. Patientinnen mit ctDNA-Persistenz werden zu Pembrolizumab vs. Observation randomisiert. In Deutschland ist die Untersuchung der Relevanz von Liquid Biopsy in der Nachsorge in der von der Universitäts-Frauenklinik Ulm initiierten SURVIVEStudie geplant.

\section{Liquid-Biopsy-basierte Therapieinterventionen}

Der Etablierung blutbasierter Biomarker in der Praxis beim frühen Mammakarzinom steht bis jetzt die Unsicherheit hinsichtlich der klinischen Konsequenz im Wege. Eine der wenigen Studien, die eine mögliche CTC-basierte Therapieintervention im nicht metastasierten Setting untersucht haben, war die multizentrische Treat CTC-Studie [50]. Hierbei wurden Patientinnen mit HER2-negativem Primärtumor und persistierenden CTCs nach Abschluss der (neo)adjuvanten Chemotherapie zu 6 Zyklen Trastuzumab vs.
Beobachtung randomisiert. Insgesamt wurde 1317 Patientinnen gescreent. Bei 95 wurden CTCs detektiert, davon konnten 63 erfolgreich randomisiert werden. Der primäre Endpunkt (erfolgreiche Elimination der CTCs durch Trastuzumab) wurde nicht erreicht, sodass die Studie abgebrochen wurde. Auch das klinische Outcome verbesserte sich durch die HER2-zielgerichtete Therapie nicht: nach einer medianen Follow-up-Zeit von 13 Monaten waren das invasiv-krankheitsfreie sowie das Gesamtüberleben in beiden Armen gleich. Bei der Bewertung dieses Ergebnisses müssen die genauen Einschlusskriterien berücksichtigt werden. Der HER2Status der CTCs hatte auf eine mögliche Studienteilnahme keinen Einfluss. So konnten auch Patientinnen mit HER2-negativen CTCS randomisiert werden, die erwartungsgemäß von Trastuzumab nicht profitiert haben. Bei der Planung künftiger Studien sollten die phäno- bzw. genotypischen Eigenschaften der detektierten Zellen möglichst berücksichtigt werden.

\section{Klinische Einsatzgebiete der Liquid Biopsy beim metastasierten Mammakarzinom}

\section{Verbesserung der Prognoseeinschätzung}

Auch im metastasierten Setting kann die CTC-Detektion die Prognoseeinschätzung ergänzen. 2019 wurden Krankheitsverläufe von 2436 Patientinnen mit metastasierter Erkrankung aus 18 Zentren in einer retrospektiven gepoolten Analyse ausgewertet [20] ( $\downarrow$ Tab. 2). $54 \%$ der Patientinnen erhielten bereits eine systemische Therapie im metastasierten Setting. Der CTC-Nachweis erfolgte in allen berücksichtigten Studien am CellSearch-System. Allerdings hat sich aufgrund der höheren Konzentration der CTCS im metastasierten Setting ein anderer Cutoff bewährt: so wurde in den meisten Studien die Zahl von 5 oder mehr CTCs pro 7,5 ml Blut als erhöht (oder CTC-high) bezeichnet. Patientinnen mit $\geq 5$ CTCs pro 7,5 ml Blut wurden in der gepoolten Analyse als $\mathrm{CTC}_{\text {aggressive }}$ und jene mit $<5$ CTCs als $\mathrm{CTC}_{\text {indolent }}$ klassifiziert. Die Analyse konnte bestätigen, dass die Präsenz von erhöhten CTCZahlen im metastasierten Setting mit einem kürzeren Gesamtüberleben signifikant korreliert (medianes OS: 36,3 bei CTC $_{\text {aggressive vs. } 16,0 \text { Monate bei }}$ CTC $_{\text {indolent }}, \mathrm{p}<0,0001$ ) und diese Assoziation bei allen Tumorsubtypen beobachtet werden kann [20]. In der multivariaten Analyse waren folgende Faktoren mit dem verkürzten OS assoziiert: Vorbehandlung, schlechte Differenzierung, triple-negativer Phänotyp, viszerale Metastasierung und Präsenz von $\geq 5$ CTCs, wobei die CTC-Zahl der stärkste Prädiktor für das OS war (HR 2,71, 95 \%-KI 2,35-3,12, p<0,0001).

Wenige Studien untersuchten die prognostische Wertigkeit der zirkulierenden DNA in der metastasierten Situation ( $\triangleright$ Tab. 3). Shaw et al. analysierten Blutproben von 112 vorbehandelten Patientinnen [28]. Erhöhte cfDNA-Werte korrelierten mit verkürztem Gesamtüberleben. Zusätzlich wurden die ctDNA durch Nachweis von Mutationen in den Genen PIK3CA, TP53, ESR1 und KRAS sowie CTCs bestimmt. Interessanterweise wurden erhöhte cfDNA-Werte meist gleichzeitig mit hohen ctDNA-Werten nachgewiesen. Hinsichtlich des Mutationsprofils reflektierte die ctDNA die Mutationen, die in den CTCs detektiert werden konnten. 


\section{Therapiemonitoring mittels Liquid Biopsy}

Das klinische Ansprechen wird im metastasierten Setting mehreren Studien zufolge von den Veränderungen der CTC-Zahlen reflektiert [16]. Bereits nach dem 1. Zyklus einer palliativen Chemotherapie zeichnet sich in der Regel ein starker Abfall der CTCs ab. So konnten Smerage et al. sowie Martin et al. zeigen, dass bei $47-57 \%$ der Patientinnen mit initial $\geq 5$ CTCs nach dem 1 . Zyklus der Therapie $<5$ CTCs detektiert werden konnten [51, 52]. Hingegen weisen konstant hohe CTC-Zahlen 3-4 Wochen nach Beginn der Behandlung auf ein erhöhtes Progressionsrisiko hin. Auf diese Weise kann das Ansprechen schneller als mit der klassischen radiologischen Diagnostik beurteilt werden. Unklar bleibt jedoch, welche klinische Konsequenz aus den persistent hohen CTC-Zahlen abgeleitet werden soll. Diese Fragestellung wurde in der randomisierten PhaseIII-Studie der U.S. amerikanischen SWOG-Studiengruppe untersucht [51]. Insgesamt erhielten 595 Patientinnen mit metastasiertem Mammakarzinom im Rahmen der Studie ihre Erstlinienchemotherapie. Unter den 319 Frauen mit erhöhten CTC-Zahlen vor Beginn der Behandlung wiesen $43 \%$ auch nach dem 1. Zyklus $\geq 5$ CTCs auf. Diese Patientinnen wurden zur Umstellung der Therapie auf ein anderes Regime vs. Fortführung der Therapie ohne Änderung randomisiert. Das beste Überleben wiesen Patientinnen mit initial niedrigen CTC-Zahlen auf (35 Monate), gefolgt von Frauen, deren initial hohe CTC-Zahlen nach dem 1. Zyklus abfielen (23 Monate), und Patientinnen mit CTC-Persistenz (13 Monate). Interessanterweise führte die Therapieumstellung nicht zur erhofften Verbesserung der Prognose, sodass die CTC-Persistenz eine Resistenz gegenüber konventionellen zytotoxischen Substanzen voraussagt. Möglicherweise könnten Patientinnen mit persistent hohen CTC-Zahlen von immunologischen, zielgerichteten oder experimentellen Ansätzen profitieren.

Der Nachweis von zirkulierender DNA wurde in translationalen Begleitprogrammen mehrerer Studien integriert. Hrebien et al. sind im Rahmen der BEECH-Studie der Frage nachgegangen, wie die seriellen ctDNA-Messungen das Monitoring unter einer Chemotherapie ergänzen können [53]. In dieser randomisierten Phase-II-Studie erhielten Patientinnen mit ER-positiven HER2-negativen Tumoren eine Erstlinientherapie mit Paclitaxel und AKT-Inhibitor Capivasertib vs. Placebo. Zunächst wurden Mutationen in den Baseline-Proben evaluiert, die im Verlauf mittels mutationsspezifischer ddPCR detektiert wurden. Bereits eine Woche nach Beginn der Therapie wurden Veränderungen der ctDNA-Level beobachtet, die das progressionsfreie Überleben voraussagen konnten. Die beste Korrelation mit dem progressionsfreien Überleben (PFS) wurde für die Blutentnahme am Tag 1 des 2. Therapiezyklus (q4w) gezeigt (11,1 vs. 6,4 Monate, Hazard Ratio 0,2). In beiden Armen wurde ein ähnlich starker ctDNAAbfall verzeichnet, was den mittlerweile gezeigten fehlenden klinischen Benefit von Capivasertib widerspiegelt.

Auch im Rahmen der PALOMA-3-Studie konnte eine hohe Relevanz der frühen ctDNA-Untersuchung bestätigt werden [54]. In der Phase-III-Studie wurden insgesamt 521 Patientinnen nach Progress unter endokriner Therapie zur Behandlung mit Fulvestrant und CDK4/6-Inhibitor Palbociclib vs. Placebo randomisiert. Bei 455 Studienteilnehmerinnen wurde die Blutprobe vor Beginn der Behandlung mittels Multiplex-dPCR auf Hotspot-Mutationen im
PIK3CA-Gen hin untersucht. Mindestens eine Mutation wurde bei 100 Frauen detektiert, bei 73 wurde auch am Tag 15 der Behandlung eine Blutprobe analysiert. Bei Patientinnen im PalbociclibArm wurde ein deutlich stärkerer Abfall der ctDNA zwischen Baseline und Tag 15 als im Placeboarm beobachtet. Basierend auf diesen Ergebnissen lässt sich vermuten, dass die ctDNA-Dynamik als geeigneter Surrogatparameter für die frühe Beurteilung des Benefits neuer Substanzen dienen kann.

Auf dem ASCO-Symposium 2020 wurden die Ergebnisse von 2 CDK4/6-Studien vorgestellt, die ctDNA-Messungen in ihren translationalen Begleitprogrammen untersucht hatten [55, 56]. In der PADA-1-Studie wurde die klinische Bedeutung der in der zellfreien DNA detektierten ESR1-Mutation unter der Therapie mit Aromatasehemmer und Palbociclib bei 1017 Patientinnen evaluiert [56]. Alle Patientinnen hatten eine ER-positive HER2negative metastasierte Erkrankung und erhielten die Erstlinientherapie im Rahmen der Studie. Die seriellen Blutproben wurden mittels ddPCR untersucht. Vor Beginn der Therapie konnte die ESR1-Mutation bei 3,2\% der Patientinnen nachgewiesen werden; meist handelte es sich um Frauen, die bereits in der Adjuvanz mit einem Aromatasehemmer behandelt wurden. Bei $78 \%$ der Patientinnen wurde die Mutation aus der cfDNA innerhalb der ersten 5 Monate der Therapie eliminiert. Patientinnen mit Mutation im ESR1-Gen vor Beginn der Behandlung wiesen ein kürzeres PFS auf als Frauen ohne eine Mutation in der cfDNA. Wie sich diese Ergebnisse auf die Therapieentscheidungen bei den ESR $1_{\text {mut }}{ }^{-}$ Patientinnen im klinischen Alltag auswirken könnte, bleibt noch offen. Des Weiteren wurde auf dem ASCO-Symposium 2020 die Analyse von ctDNA im Rahmen der 3 Ribociclib-Studien MONALEESA-2, -3 und -7 vorgestellt [55]. Insgesamt wurden die Blutproben von 1503 Patientinnen vor Beginn der endokrin basierten Therapie auf Alterationen in 557 Genen mittels NGS hin untersucht. Alterationen in den Genen FRS2, PRKCA, MDM1, ERBB2, AKT1 und BRCA1/2 sagten einen stärkeren PFS-Benefit von Ribociclib voraus (statistischer Trend), während Patientinnen mit Alterationen in den Genen CHD4, BCL11B, ATM und CDKN2A/2B/2C von Ribociclib wenig bis gar nicht profitierten. Künftige Studien müssen klären, ob die untersuchten Gene zur frühzeitigen Detektion von Resistenzen im Rahmen des Therapiemonitorings beitragen können.

\section{Liquid-Biopsy-basierte Therapieinterventionen}

Die Therapie der metastasierten Patientin orientiert sich heutzutage an den prädiktiven Eigenschaften des Primärtumors bzw. der Metastasen. Dies setzt die Notwendigkeit einer invasiven Gewebeprobe zur Gewinnung des histologischen Materials voraus und kann mit Komplikationen bei erschwerter Lokalisation verbunden sein. Andererseits muss die klonale Heterogenität der Tumorerkrankung berücksichtigt werden. So können sich die einzelnen Metastasen voneinander hinsichtlich des Phäno- und Genotyps unterscheiden, aber auch innerhalb eines metastatischen Herdes können unterschiedliche Populationen nachgewiesen werden. Auch im zeitlichen Verlauf kann es zur Veränderung der untersuchten Marker kommen. Eine Metaanalyse von 39 Studien zeigte, dass 22,5\% der Patientinnen mit initial ER-positiven Primärtumoren ER-negative Metastasen entwickeln [57]. Der Verlust des HER2-Status wurde 


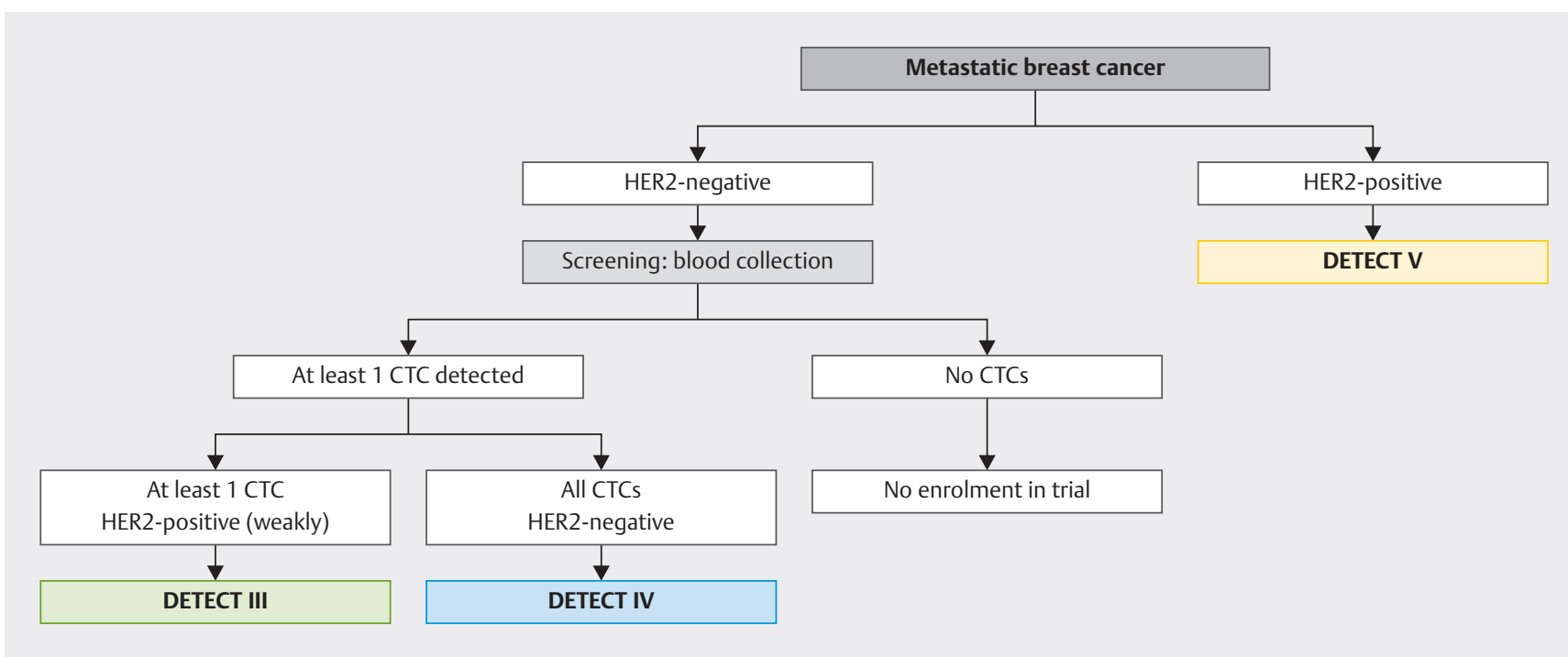

- Abb. 2 Studienalgorithmus im DETECT-Programm.

bei $21,3 \%$ der Patientinnen beobachtet. Hingegen entwickelten 9,5\% der Patientinnen mit HER2-negativen Primärtumoren eine HER2-positive Metastase. Aus diesem Grund empfiehlt die AGOKommission Mamma eine Reevaluation des Rezeptorstatus im metastasierten Setting.

Unter der Annahme, dass die blutbasierten Biomarker die Eigenschaften der dominanten Tumorpopulationen widerspiegeln, wird der mögliche Einsatz der Liquid Biopsy als Grundlage der Therapieentscheidung intensiv diskutiert.

Zu den wichtigsten Studien, die eine CTC-basierte Therapiewahl untersuchten, gehört die STIC CTC-Studie [58]. In dieser Phase-III-Studie wurden insgesamt 778 Frauen mit hormonrezeptorpositiver HER2-negativer Erkrankung vor Beginn der Erstlinientherapie randomisiert. Im CTC-Arm basierte die Therapiewahl ausschließlich auf dem Ergebnis der Blutuntersuchung: Patientinnen mit < 5 CTCs erhielten eine endokrine Monotherapie, während bei $\geq 5$ CTCs eine Chemotherapie verabreicht wurde. Im Kontrollarm wurde ebenfalls Blut abgenommen und mittels CellSearch untersucht, das Ergebnis blieb jedoch verblindet. In diesem Arm wurde die Therapie vom behandelnden Arzt anhand der üblichen klinischen Kriterien gewählt. Da die Studie 2012 initiiert wurde, wurden die erst später zugelassenen CDK4/6-Inhibitoren im Studiendesign nicht berücksichtigt. Die STIC CTC-Studie erreichte ihren primären Endpunkt: die CTC-basierte Therapiewahl war der ärztlichen Entscheidung, die als „treatment of physician's choice" bezeichnet wird, nicht unterlegen. Das klinische Outcome (PFS und OS) war in beiden Armen gleich. Interessanterweise profitierten die Patientinnen mit diskordanter Einschätzung des Risikos (klinisch low-risk, aber mit hohen CTC-Zahlen oder klinisch high-risk mit niedrigen (TC-Zahlen) hinsichtlich des Gesamtüberlebens von einer Chemotherapie. Da in der STIC CTCStudie keine endokrin basierte Kombinationstherapie mit CDK4/6-Inhibitoren, derzeit die am häufigsten gewählte Erstlinientherapie im hormonrezeptorpositiven Kollektiv, möglich war, kann momentan keine aus dieser Studie resultierende Empfehlung für den klinischen Alltag ausgesprochen werden.
Im Gegensatz zur STIC CTC-Studie, welche die CTC-Zahlen als Grundlage der Therapieentscheidung untersucht hatte, ist die Cir-Ce T-DM1-Studie der Frage nachgegangen, wie die Eigenschaften der CTCs die Therapiewahl beeinflussen können [59]. Hierbei wurde untersucht, ob Patientinnen mit histologisch HER2-negativer Erkrankung (bestimmt am Primärtumor und/ oder Metastase) deren CTCs einen positiven HER2-Status aufweisen, von einer HER2-zielgerichteten Therapie profitieren können. Insgesamt wurden 154 Frauen mit vorbehandeltem Mammakarzinom auf HER2-amplifizierte CTCs mittels FisH gescreent. In 14 Fällen konnte mindestens eine HER2-positive CTC nachgewiesen werden, von denen 11 mit T-DM1 im Rahmen der Studie zielgerichtet behandelt wurden. Die Ansprechrate war mit 9,1\% sehr gering. Es konnte nur eine partielle Remission erreicht werden. Das mediane PFS betrug 4,8 Monate und das OS 9,5 Monate. Möglicherweise kann der fehlende Benefit der HER2-zielgerichteten Therapie durch die Heterogenität der CTCs erklärt werden. So wies die Mehrheit der detektierten CTCs einen negativen HER2Status auf und nur bei 4,4\% der CTCs konnte HER2-Amplifikation nachgewiesen werden.

Weitere CTC-basierte Therapiekonzepte werden derzeit in den DETECT-Studien, das weltweit größte Studienprogramm zu CTCbasierten Therapieinterventionen, untersucht [50] ( $\triangleright$ Abb. 2).

Im Gegensatz zur CTC-Diagnostik kann die ctDNA bereits heute im klinischen Alltag bei der Therapiewahl berücksichtigt werden. Mehreren Studien zufolge können somatische genetische Alterationen in den Genen PIK3CA, ESR1, HER2 und PTEN nachgewiesen und im Sinne von „targetable mutations“ zielgerichtet angegangen werden ( $\triangleright$ Tab. 7).

Die erste Substanz mit der Liquid-Biopsy-basierten Indikation wurde auf Basis der SOLAR 1-Studie zugelassen [30]. Hierbei wurde der PI3K-Inhibitor Alpelisib bei Patientinnen mit hormonrezeptorpositiver HER2-negativer Erkrankung in Kombination mit Fulvestrant untersucht. Alpelisib hemmt das vom PIK3CA-Gen kodierte Enzym PI3-Kinase. Die Mutationen im PIK3CA-Gen werden bei bis zu $40 \%$ der Patientinnen im fortgeschrittenen Stadium beobachtet 
- Tab. 7 Mögliche in der ctDNA detektierbare Alterationen und deren potenzielle Bedeutung.

\begin{tabular}{|c|c|}
\hline Gen/Marker & potenzielle klinische Relevanz \\
\hline ESR1 & 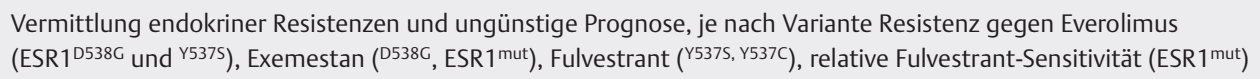 \\
\hline PIK3CA & $\begin{array}{l}\text { Prädiktion des Ansprechens auf Therapie mit PI3K-Inhibitor (Alpelisib-Zulassung in Deutschland 7/2020); potenziell } \\
\text { einsetzbar beim Therapiemonitoring }\end{array}$ \\
\hline AKT1 & Prädiktion des Ansprechens auf AKT-Inhibitoren wie Capivasertib (AKT1E17K) \\
\hline HER2 & Prädiktion des Ansprechens auf Neratinib bei HER2 ${ }^{\text {mut }}$ Therapiemonitoring unter Anti-HER2-Therapie \\
\hline TP53 & Vermittlung der Therapieresistenzen \\
\hline PTEN & Vermittlung der Therapieresistenzen \\
\hline BRCA & Prädiktion des Ansprechens auf PARP-Inhibitoren und Platinsalze bei somatischen BRCAMutationen in der ctDNA \\
\hline $\begin{array}{l}\text { Mikrosatelliteninstabilität (MSI), } \\
\text { Verlust der Heterozygotie (LOH) }\end{array}$ & Prädiktion des Ansprechens auf zielgerichtete und immunologische Therapieansätze \\
\hline
\end{tabular}

- Tab. 8 Klinische Relevanz der CTCs und der zirkulierenden DNA bei Mammakarzinom.

\begin{tabular}{|c|c|c|c|}
\hline & & CTCs & zirkulierende DNA \\
\hline \multirow[t]{4}{*}{ M0 } & prognostische Relevanz & sehr hoch (in Metaanalysen bestätigt) & $\begin{array}{l}\text { vermutlich hoch; Limitation: kleine Fallzahlen, relativ } \\
\text { kurzes Follow up, methodische Unterschiede }\end{array}$ \\
\hline & Therapiemonitoring & $\begin{array}{l}\text { Persistenz nach (neo)adjuvanter Chemotherapie sagt } \\
\text { schlechteres Outcome voraus }\end{array}$ & $\begin{array}{l}\text { Persistenz nach (neo)adjuvanter Chemotherapie } \\
\text { sagt schlechteres Outcome voraus; Korrelation der } \\
\text { ctDNA-Dynamik mit pCR }\end{array}$ \\
\hline & Ergänzung der Nachsorge & $\begin{array}{l}\text { potenziell relevant, insb. bei HR-positiver Erkrankung: } \\
\text { CTC-Detektion } 5 \text { Jahre nach Diagnose sagt ein erhöhtes } \\
\text { Rezidivrisiko voraus }\end{array}$ & $\begin{array}{l}\text { potenziell relevant: ctDNA-Positivität sagt ein } \\
\text { erhöhtes Rezidivrisiko voraus }\end{array}$ \\
\hline & $\begin{array}{l}\text { Liquid-Biopsybasierte Thera- } \\
\text { pieinterventionen }\end{array}$ & $\begin{array}{l}\text { bisher keine positiven Studien, Potenzial unklar; kein } \\
\text { Benefit von Trastuzumab bei CTC-Persistenz in der } \\
\text { TREAT CTC-Studie (HER2-Status der CTCs nicht } \\
\text { berücksichtigt) }\end{array}$ & bisher keine positiven Studien, Potenzial unklar \\
\hline \multirow[t]{3}{*}{ M1 } & prognostische Relevanz & sehr hoch (in Metaanalysen bestätigt) & $\begin{array}{l}\text { vermutlich hoch; Limitation: wenige Studien, kleine } \\
\text { Fallzahlen, methodische Unterschiede }\end{array}$ \\
\hline & Therapiemonitoring & $\begin{array}{l}\text { hohes Potenzial: Persistenz nach dem 1. Zyklus } \\
\text { Chemotherapie korreliert mit dem Ansprechen, } \\
\text { klinische Konsequenz unklar }\end{array}$ & $\begin{array}{l}\text { hohes Potenzial: Persistenz nach dem 1. Zyklus der } \\
\text { Therapie korreliert mit dem Ansprechen, Klinische } \\
\text { Konsequenz unklar }\end{array}$ \\
\hline & $\begin{array}{l}\text { Liquid-Biopsybasierte } \\
\text { Therapieinterventionen }\end{array}$ & $\begin{array}{l}\text { erste positive Studie (STIC CTC): CTC-basierte Wahl } \\
\text { der Erstlinientherapie ist der Wahl des Onkologen nicht } \\
\text { unterlegen; klinische Konsequenz unklar; weitere } \\
\text { Studien ausstehend (z. B. DETECT-Studienprogramm) }\end{array}$ & $\begin{array}{l}\text { Haupteinsatzgebiet: Detektion von somatischen } \\
\text { Mutationen in der ctDNA als Indikationsgrundlage } \\
\text { für zielgerichtete Therapie: Alpelisib bei Patientin- } \\
\text { nen mit Mutation im PIK3CA-Gen in den USA und } \\
\text { Europa zugelassen. }\end{array}$ \\
\hline
\end{tabular}

und führen durch Aktivierung der PI3K/Akt/mTOR-Signalkaskade zur gesteigerten Aggressivität der Erkrankung. In der SOLAR 1-Studie wurden insgesamt 572 Patientinnen zur Therapie mit Fulvestrant und Alpelisib vs. Fulvestrant und Placebo randomisiert. Die Patientinnen waren metastasiert und bereits endokrin vorbehandelt. Bei allen Frauen wurde der PIK3CA-Mutationsstatus im Tumorgewebe und bei einem Teil auch in der ctDNA bestimmt. Der Nachweis einer Mutation war mit einem signifikanten PFSBenefit durch Hinzunahme von Alpelisib assoziiert - unabhängig davon, ob die Mutation im Gewebe oder in der ctDNA detektiert wurde. Alpelisib wurde bereits 2019 in den USA und 2020 in Europa zugelassen. In Europa wurde das Medikament durch das Committee for Medicinal Products for Human Use (CHMP) positiv bewertet, die Zulassung wird im Sommer 2020 erwartet.

Mit modernen Sequenzierungstechniken ist es möglich, mehrere potenziell therapierelevante Mutationen gleichzeitig zu untersuchen. Diesen Ansatz verfolgte die PlasmaMatch-Studie [60], in welcher Blutproben von insgesamt 1044 Frauen mit metastasiertem Mammakarzinom gescreent wurden. Dabei wurde eine Reihe von genetischen Alterationen in der ctDNA detektiert. 
Am häufigsten war das TP53-Gen betroffen (44,1\%), gefolgt von PIK3CA (34,9\%), ESR1 (Estrogen-Rezeptor 1) (33,1\%), PTEN (6,9\%), HER2 (6,4\%) und AKT1 (5,0\%). Im Studiendesign war eine Mutations-getriggerte zielgerichtete Behandlung vorgesehen. So wurden beispielsweise Patientinnen mit Mutationen im ESR1-Gen mit Fulvestrant therapiert, und bei einer Mutation im HER2-Gen erhielten die Frauen die Anti-HER2-Therapie mit Neratinib. Im Falle von Mutationen im PTEN- bzw. AKT1-Gen wurde die Behandlung mit Capivasertib initiiert. Nach Analyse des Ansprechens erwies sich insbesondere die Therapie mit Neratinib und Capivasertib als vielversprechend (Ansprechraten: Neratinib $25 \%$, Capivasertib 22-33\%).

Der aktuelle Wissensstand zur Liquid Biopsy beim frühen und fortgeschrittenen Mammakarzinom wurde in der $>$ Tab. 8 zusammengefasst.

\section{Fazit}

- Unter Liquid Biopsy wird die Untersuchung von zirkulierenden Tumorzellen und Nukleinsäuren (DNA/RNA) im Blut verstanden.

- Die prognostische Relevanz der CTC-Detektion bei Patientinnen mit Mammakarzinom ist sowohl im frühen als auch immetastasierten Stadium sehr hoch.

- Die Dynamik der CTCs und der ctDNA korreliert mit Ansprechen auf eine palliative Therapie.

- Im Fokus der translationalen onkologischen Forschung stehen heutzutage die Liquid-Biopsy-basierten Therapieinterventionen beim metastasierten Mammakarzinom. Der PI3K-Inhibitor Alpelisib ist die erste Substanz, die in diesem Kontext zugelassen wurde.

Interessenkonflikt

Die Autorinnen/Autoren geben an, dass kein Interessenkonflikt besteht.

\section{Literatur}

[1] Fisher B, Ravdin RG, Ausman RK et al. Surgical adjuvant chemotherapy in cancer of the breast: results of a decade of cooperative investigation. Ann Surg 1968; 168: 337-356

[2] Banys M, Hahn M, Gruber I et al. Detection and clinical relevance of hematogenous tumor cell dissemination in patients with ductal carcinoma in situ. Breast Cancer Res Treat 2014; 144: 531-538

[3] Luzzi K], MacDonald IC, Schmidt EE et al. Multistep nature of metastatic inefficiency: dormancy of solitary cells after successful extravasation and limited survival of early micrometastases. Am J Pathol 1998; 153: 865873

[4] Mehes G, Witt A, Kubista E et al. Circulating breast cancer cells are frequently apoptotic. Am J Pathol 2001; 159: 17-20

[5] Meng S, Tripathy D, Frenkel EP et al. Circulating tumor cells in patients with breast cancer dormancy. Clin Cancer Res 2004; 10: 8152-8162

[6] Krawczyk N, Meier-Stiegen F, Banys M et al. Expression of stem cell and epithelial-mesenchymal transition markers in circulating tumor cells of breast cancer patients. Biomed Res Int 2014; 2014: 415721

[7] Mani SA, Guo W, Liao MJ et al. The epithelial-mesenchymal transition generates cells with properties of stem cells. Cell 2008; 133: 704-715

[8] Brabletz T. EMT and MET in metastasis: where are the cancer stem cells? Cancer Cell 2012; 22: 699-701
[9] Schwarzenbach H, Pantel K, Kemper B et al. Comparative evaluation of cell-free tumor DNA in blood and disseminated tumor cells in bone marrow of patients with primary breast cancer. Breast Cancer Res 2009; 11: R71

[10] Schwarzenbach H, Hoon DS, Pantel K. Cell-free nucleic acids as biomarkers in cancer patients. Nat Rev Cancer 2011; 11: 426-437

[11] Ignatiadis M, Riethdorf S, Bidard FC et al. International study on interreader variability for circulating tumor cells in breast cancer. Breast Cancer Res 2014; 16: R43

[12] Allard WJ, Matera J, Miller MC et al. Tumor cells circulate in the peripheral blood of allmajor carcinomas but not in healthy subjects or patients with nonmalignant diseases. Clin Cancer Res 2004; 10: 6897-6904

[13] Fehm T, Braun S, Muller V et al. A concept for the standardized detection of disseminated tumor cells in bone marrow from patients with primary breast cancer and its clinical implementation. Cancer 2006; 107: 885892

[14] Fehm TN, Meier-Stiegen F, Driemel C et al. Diagnostic leukapheresis for CTC analysis in breast cancer patients: CTC frequency, clinical experiences and recommendations for standardized reporting. Cytometry A 2018; 93: 1213-1219

[15] Alix-Panabieres C, Pantel K. Clinical Applications of Circulating Tumor Cells and Circulating Tumor DNA as Liquid Biopsy. Cancer Discov 2016; 6: 479-491

[16] [Anonym]. Colloquium Senologie 2019/2020. München: LUKON Verlagsgesellschaft mbH. 2019

[17] Jung A, Kirchner T. Liquid Biopsy in Tumor Genetic Diagnosis. Dtsch Arztebl Int 2018; 115: 169-174

[18] Husemann Y, Geigl JB, Schubert F et al. Systemic spread is an early step in breast cancer. Cancer Cell 2008; 13: 58-68

[19] Janni W], Rack B, Terstappen LW et al. Pooled Analysis of the Prognostic Relevance of Circulating Tumor Cells in Primary Breast Cancer. Clin Cancer Res 2016; 22: 2583-2593

[20] Cristofanilli M, Pierga JY, Reuben J et al. The clinical use of circulating tumor cells (CTCs) enumeration for staging of metastatic breast cancer (MBC): International expert consensus paper. Crit Rev Oncol Hematol 2019; 134: 39-45

[21] Bidard FC, Michiels S, Riethdorf S et al. Circulating Tumor Cells in Breast Cancer Patients Treated by Neoadjuvant Chemotherapy: A Meta-analysis. J Natl Cancer Inst 2018; 110: 560-567

[22] Tan G, Chu C, Gui X et al. The prognostic value of circulating cell-free DNA in breast cancer: A meta-analysis. Medicine (Baltimore) 2018; 97 : e0197

[23] Fujita N, Nakayama T, Yamamoto N et al. Methylated DNA and total DNA in serum detected by one-step methylation-specific PCR is predictive of poor prognosis for breast cancer patients. Oncology 2012; 83: 273-282

[24] Fernandez-Garcia D, Hills A, Page K et al. Plasma cell-free DNA (cfDNA) as a predictive and prognostic marker in patients with metastatic breast cancer. Breast Cancer Res 2019; 21: 149

[25] Radovich M, Jiang G, Chitambar C et al. Detection of circulating tumor DNA (ctDNA) after neoadjuvant chemotherapy is significantly associated with disease recurrence in early-stage triple-negative breast cancer (TNBC): Preplanned correlative results from clinical trial BRE12158. San Antonio Breast Cancer Symposium. 2019. Abstr. GS5-02

[26] Garcia JM, Garcia V, Silva J et al. Extracellular tumor DNA in plasma and overall survival in breast cancer patients. Genes Chromosomes Cancer 2006; 45: 692-701

[27] Fujita N, Kagara N, Yamamoto $\mathrm{N}$ et al. Methylated DNA and high total DNA levels in the serum of patients with breast cancer following neoadjuvant chemotherapy are predictive of a poor prognosis. Oncol Lett 2014; 8: 397-403 
[28] Shaw JA, Guttery DS, Hills A et al. Mutation Analysis of Cell-Free DNA and Single Circulating Tumor Cells in Metastatic Breast Cancer Patients with High Circulating Tumor Cell Counts. Clin Cancer Res 2017; 23: 88-96

[29] Oshiro C, Kagara N, Naoi Y et al. PIK3CA mutations in serum DNA are predictive of recurrence in primary breast cancer patients. Breast Cancer Res Treat 2015; 150: 299-307

[30] Fehm T, Neubauer H, Banys-Paluchowski M. Liquid Biopsy. In: Untch M, Harbeck N, Thomssen C, Hrsg. Colloquium Senologie 2019/2020. München: LUKON Verlag; 2019

[31] Rack B, Schindlbeck C, Juckstock J et al. Circulating tumor cells predict survival in early average-to-high risk breast cancer patients. J Natl Cancer Inst 2014; 106: dju066

[32] Riethdorf S, Muller V, Zhang L et al. Detection and HER2 expression of circulating tumor cells: prospective monitoring in breast cancer patients treated in the neoadjuvant GeparQuattro trial. Clin Cancer Res 2010; 16: 2634-2645

[33] Kasimir-Bauer S, Bittner AK, Konig L et al. Does primary neoadjuvant systemic therapy eradicate minimal residual disease? Analysis of disseminated and circulating tumor cells before and after therapy. Breast Cancer Res 2016; 18: 20

[34] Li S, Lai H, Liu J et al. Circulating Tumor DNA Predicts the Response and Prognosis in Patients With Early Breast Cancer Receiving Neoadjuvant Chemotherapy. JCO Precision Oncology 2020; 4: 244-257

[35] Magbanua MJM, Brown-Swigart L, Wu HT et al. Circulating tumor DNA in neoadjuvant treated breast cancer reflects response and survival. medRxiv 2020. doi:10.1101/2020.02.03.20019760

[36] Takahashi H, Kagara N, Tanei T et al. Correlation of Methylated Circulating Tumor DNA With Response to Neoadjuvant Chemotherapy in Breast Cancer Patients. Clin Breast Cancer 2017; 17: 61-69

[37] Rothe F, Silva M], Venet D et al. Circulating Tumor DNA in HER2-Amplified Breast Cancer: A Translational Research Substudy of the NeoALTTO Phase III Trial. Clin Cancer Res 2019; 25: 3581-3588

[38] Garcia-Murillas I, Schiavon G, Weigelt B et al. Mutation tracking in circulating tumor DNA predicts relapse in early breast cancer. Sci Transl Med 2015; 7: 302ra133

[39] Sharma G, Mirza S, Parshad R et al. DNA methylation of circulating DNA: a marker for monitoring efficacy of neoadjuvant chemotherapy in breast cancer patients. Tumour Biol 2012; 33: 1837-1843

[40] Moss J, Zick A, Grinshpun A et al. Circulating breast-derived DNA allows universal detection andmonitoring of localized breast cancer. Ann Oncol 2020; 31: 395-403

[41] Diagnostik und Therapie früher und fortgeschrittener Mammakarzinome. Herausgegeben von der Kommission Mamma (vertreten durch: Wolfgang Janni) der Arbeitsgemeinschaft Gynäkologische Onkologie e. V. in der Deutschen Gesellschaft für Gynäkologie und Geburtshilfe e. V. sowie in der Deutschen Krebsgesellschaft e. V. 2020.

[42] Leitlinienprogramm Onkologie (Deutsche Krebsgesellschaft, Deutsche Krebshilfe, AWMF): S3-Leitlinie Früherkennung, Diagnose, Therapie und Nachsorge des Mammakarzinoms, Version 4.3, AWMF Registernummer: 032-045OL. 2020. Online (Stand: 18.09.2020): http://www.leitlinienpro gramm-onkologie.de/leitlinien/mammakarzinom/

[43] Fiegl H, Millinger S, Mueller-Holzner E et al. Circulating tumor-specific DNA: a marker for monitoring efficacy of adjuvant therapy in cancer patients. Cancer Res 2005; 65: 1141-1145

[44] Garcia-Murillas I, Chopra N, Comino-Mendez I et al. Assessment of Molecular Relapse Detection in Early-Stage Breast Cancer. JAMA Oncol 2019. doi:10.1001/jamaoncol.2019.1838
[45] Coombes RC, Page K, Salari R et al. Personalized Detection of Circulating Tumor DNA Antedates Breast Cancer Metastatic Recurrence. Clin Cancer Res 2019; 25: 4255-4263

[46] Olsson E, Winter C, George A et al. Serial monitoring of circulating tumor DNA in patients with primary breast cancer for detection of occult metastatic disease. EMBO Mol Med 2015; 7: 1034-1047

[47] Sparano JA, O'Neill A, Alpaugh K et al. Circulating tumor cells (CTCs) five years after diagnosis are prognostic for late recurrence in operable stage II-III breast cancer. San Antonio Breast Cancer Symposium. 2017. Abstr. GS6-03

[48] Sparano J, O'Neill A, Alpaugh K et al. Association of Circulating Tumor Cells With Late Recurrence of Estrogen Receptor-Positive Breast Cancer: A Secondary Analysis of a Randomized Clinical Trial. JAMA Oncol 2018. doi:10.1001/jamaoncol.2018.2574

[49] Janni W, Rack B, Fasching P et al. Persistence of circulating tumor cells in high risk early breast cancer patients five years after adjuvant chemotherapy and late recurrence: Results from the adjuvant SUCCESS A trial. J Clin Oncol 2018; 36 (15): 515 doi:10.1200/JCO.2018.36.15_suppl.515

[50] Banys-Paluchowski M, Fehm T, Janni W et al. Circulating and Disseminated Tumor Cells in Breast Carcinoma: Report from the Consensus Conference on Tumor Cell Dissemination during the 39th Annual Meeting of the German Society of Senology, Berlin, 27 June 2019. Geburtshilfe Frauenheilkd 2019; 79: 1320-1327

[51] Smerage JB, Barlow WE, Hortobagyi GN et al. Circulating tumor cells and response to chemotherapy in metastatic breast cancer: SWOG S0500. J Clin Oncol 2014; 32: 3483-3489

[52] Martin M, Custodio S, de Las Casas ML et al. Circulating tumor cells following first chemotherapy cycle: an early and strong predictor of outcome in patients with metastatic breast cancer. Oncologist 2013; 18: 917-923

[53] Hrebien S, Citi V, Garcia-Murillas I et al. Early ctDNA dynamics as a surrogate for progression-free survival in advanced breast cancer in the BEECH trial. Ann Oncol 2019; 30: 945-952

[54] O'Leary B, Hrebien S, Morden JP et al. Early circulating tumor DNA dynamics and clonal selection with palbociclib and fulvestrant for breast cancer. Nat Commun 2018; 9: 896

[55] Andre F, Su F, Solovieff $\mathrm{N}$ et al. Pooled ctDNA analysis of the MONALEESA (ML) phase III advanced breast cancer (ABC) trials. J Clin Oncol 2020; 38 (Suppl.); Abstr. 1009

[56] Bidard FC, Callens C, Dalenc F et al. Prognostic impact of ESR1 mutations in ER+ HER2-MBC patients prior treated with first line $\mathrm{Al}$ and palbociclib: An exploratory analysis of the PADA-1 trial. J Clin Oncol 2020; 38 (15): 1010 doi:10.1200/JCO.2020.38.15_suppl.1010

[57] Schrijver W, Suijkerbuijk KPM, van Gils CH et al. Receptor Conversion in Distant Breast Cancer Metastases: A Systematic Review and Metaanalysis. J Natl Cancer Inst 2018; 110: 568-580

[58] Bidard FC, Jacot W, Dureau S et al. Abstract GS3-07: Clinical utility of circulating tumor cell count as a tool to chose between first line hormone therapy and chemotherapy for ER+ HER2-metastatic breast cancer: Results of the phase III STIC CTC trial. Cancer Res 2019. doi:10.1158/1538-7445.SABCS18-GS3-07

[59] Jacot W, Cottu P, Berger F et al. Actionability of HER2-amplified circulating tumor cells in HER2-negative metastatic breast cancer: the CirCe T-DM1 trial. Breast Cancer Res 2019; 21: 121

[60] Turner N, Kingston B, Kilburn L et al. Results from the plasmaMATCH trial: A multiple parallel cohort, multi-centre clinical trial of circulating tumour DNA testing to direct targeted therapies in patients with advanced breast cancer (CRUK/15/010). San Antonio Breast Cancer Symposium. 2019. Abstr. GS3-06 